\title{
Case Study of a Neglected Child as One of the Forms of CAN
}

\section{T. Fertalova (Terezia Fertalova), I. Ondriova (Iveta Ondriova)}

University of Presov in Presov, Slovakia

\section{E-mail address:}

iondriova@centrum.sk

\section{Reprint address:}

Terezia Fertalova

Faculty of Health Care

Department of Nursing

University of Presov in Presov

Partizanska No. 1

08001 Presov

Slovakia

Source: Clinical Social Work and Health Intervention

Pages: 23 - 29

Volume: 9

Issue: 4

\section{Reviewers:}

Andrea Shahum

University of North Carolina at Chapel Hill School of Medicine, USA

Michael Costello

University of California, San Francisco, USA

\section{Key words:}

Child. Neglect. Prevention. Case Study.

\section{Publisher:}

International Society of Applied Preventive Medicine i-gap

CSWHI 2018; 9(4): 23 - 29; DOI 10.22359/cswhi_9_4_04 ( 2018 Clinical Social Work and Health Intervention

\section{Abstract:}

Based on the findings of UNICEF which focuses on long-term and systematic help for children, there are 50 million children who are exposed to physical and psychological abuse. Unsuitable treatment of children brings a whole raft of problems which have to be addressed on the psychological, educational, legal and nursing levels. In this paper, the authors present a case study of a child hospitalized in a ward of older children and adolescents who showed typical signs of neglect. 
The term CAN Syndrome (Child Abused and Neglected Syndrome) began to be used in the 1990s. There are several definitions of CAN Syndrome in the current literature. One of them is a definition that emphasizes that it is a "conscious or unconscious act of a person responsible for the care of a child under the age of 18 which threatens the healthy development or even damages the health of the child." (Kovac 2009 p 34). One of the forms of CAN Syndrome is neglect of a child. We understand this term as referring to any insufficiency of care for the child which threatens or causes a serious deficiency in its development. Physical neglect is understood as not satisfying the child's physical needs. This includes, according to the Council of Europe's Health Committee, failure to provide adequate nutrition, clothing, shelter, healthcare or protection from harm. Most adults do not neglect children intentionally. Neglect usually results from an inability to plan or an ignorance of what is suitable child care. The forms of neglect include: non-satisfaction of the child's physical needs; inadequate and irregular nutrition; bad or no hygiene; inadequate cleanliness; quality of dress with regard to weather; particularly leaving small children without proper supervision; insufficient medical care including neglect for prevention; frequent absences from school.

The behavioral indicators of a child who is neglected include: health problems; chronic tiredness, apathy; paleness; gauntness; self-destructive tendencies; low self-esteem; running away from home; delinquency; theft; begging; consumption of alcohol and/or drugs. A neglected child feels frustration and that depresses them. Unfavorable factors have a negative impact on the child's physical and psychomotor development. Physical neglect results in failure and can lead to the death of the child. Emotional neglect and psychological deprivation involve poor satisfaction of basic mental, emotional and social needs and can lead to Deprivation Syndrome in childhood.

\section{The Consequences of CAN Syndrome}

The seriousness of the consequences depends on the extent of the destructive forces of the cruelty, abuse and neglect of the child and whether this is short-term or long-term. The degree of ability of the victim to defend themselves is also important. It is tragic when it leads the victim to break down, shatters their identity establishing lasting feelings of helplessness, dependent slavish submission and loyalty to the aggressor stemming from fear of even greater suffering that could follow if the victim did not try to appease the aggressor in every way possible. The consequences are very serious and one should not underestimate them because they affect the rest of the psychological, physical and social development of the child. The psychological and moral deficit within them deepens. Their character is significantly disturbed. At school they have worse results and can fall in with a "bad crowd". In adulthood, there are more conflicts with the law and crime. If the aggression is removed in childhood, the risk of crime in adulthood will be reduced. Girls do not get into conflict situations with the law more often than others. Their aggressive behavior in childhood is subsequently manifested in adulthood in cruel behavior towards their own children. Hromkova, 2006.

\section{The Role of Nursing in Preventing CAN \\ Syndrome}

Children who have been subjected to cruelty, abuse and neglect carry long-term injuries that are the basis of many mental illnesses, addictions, social maladaptation, asocial and antisocial behavior, criminality. It is more effective to avoid and prevent 
the recurrence and repetition of this problem by treating and assisting children who are already marked by violence. Early and effective assistance can prevent the adverse consequences of the violence. Prevention of CAN Syndrome involves family rehabilitation as one of the main forms of therapy. It means behavioral influence on the family and its members in the direction of preserving or restoring it. The Council of Europe's recommendation in this respect is to "establish a system of effective prevention, reporting, verification, investigation and evaluation, interventions or treatment and monitoring of cases of child abuse and cruelty on a multidisciplinary basis, which will also specify the role and responsibilities of the various agencies concerned." (Dunovsky 1995 p 76). Past experience and expert literature show that prevention is the guiding idea of any attempt at correction. The prevention of CAN Syndrome is based on three components: primary, secondary and tertiary prevention. Although the division of prevention into primary, secondary and tertiary is seen as unusable and is no longer recommended today because in practice the components are overlap-ping and complementary on a theoretical level this division will help us to clarify the issue.

The role of primary prevention is to prevent the onset of CAN Syndrome and, if possible, to prevent it before it happens. In particular, it is targeted at the general public and as it is a child-related Syndrome, it is also focused on children, parents and educators of children, professionals and public officials. It attempts to strengthen good relationships in families, promote education for the safety of affected children, ensure the teaching of sex education in schools, provide courses for teachers and social workers, pediatricians working in hospitals and outpatient clinics, and support conferences and seminars to discuss this topic. "Primary prevention according to the $\mathrm{WHO}$ means to prevent the occurrence of a negative social phenomenon, to suppress it immediately at its origin." (Dunovsky 1995 p 103).

Secondary prevention depends on the early diagnosis of CAN Syndrome and on collaboration between pediatricians, teachers, psychologists and social workers. The first step is to actively search for risk groups and risky life situations, where abuse is most common. The second step is to target these groups of people and situations in order to minimize the risk of CAN Syndrome. The main task of tertiary prevention is to prevent and minimize the risk of repetition of bad behavior towards children. It includes a diagnostic element (defining the extent of the harm to the child); a protective element (preventing further contact of the child with the perpetrator); a therapeutic element (eliminating the negative consequences to the child using therapy). Matejcek takes the view that primary prevention is general and does not need to be differentiated. Secondary prevention largely overlaps with the therapeutic treatment of children. It has its specific goals and processes. Tertiary interventions only relate to the consequences of harm (Matejcek 1995 p 340).

\section{Case Description}

On 9.11.2017 the Clinic of Pediatrics, Department of Older Children and Adolescents, admitted a 7-year old child referred by the pediatrician's surgery for hospitalization for impetigo in the area of the auricles, causus socialis. The child had been treated repeatedly during 10/2017 with antibiotics Cedrox, Ospamox without improvement in the condition. The primary care doctor had supposed failure to properly give antibiotic treatment by the family.

Personal History: Child of $3^{\text {rd }}$ physiological pregnancy, delivery in term, in hospital, birth weight $2,500 \mathrm{~g} / 47 \mathrm{~cm}$, breast-fed 
up to 5 months, eats everything without restrictions, vaccinated according to the vaccination schedule, psychomotor development: walks alone from one year of age, 9/2014 - Bronchopneumonia lobaris, Bronchitis acuta, Ascaridosis, Pediculosis capitis; 8/2016 Pyelonefrititis acuta, Bronchitis acuta diffusa, Tonsillopharyngitis acuta, Ascaridosis; 9/2016 Bronchopneumonia,

Family History: The mother and father are healthy, unemployed, number of siblings: 5, the younger brother (4 years old) has bronchial asthma, the others are healthy, grandmother survived stroke. Mother and father smoke, live in a "shanty" cottage, drink water from the stream.

Catamnesis: At admission the child was alert, afebrile, weight $16 \mathrm{~kg}$, height $105 \mathrm{~cm}-$ the child was hypotrophic (percentile 4), BT: $36.8^{\circ} \mathrm{C}$, BP: $80 / 55 \mathrm{~mm} \mathrm{Hg}$, Breathing: $13 / \mathrm{min}$. Upon admission the following test were ordered: FW, CRP, blood test + diff, glycaemia, urea, creatinine, mineralogram, urine $\mathrm{CH}+\mathrm{S}$, swabs from nose, throat, rectum. Nails short, dirty, hair unkempt, presence of lice in the part of the head with hair, scabies, unkempt, neglected appearance, speech clear, incomprehensible,. On both sides of the auricles from the inside and outside, in the nose, on the chest and on the back and on both upper limbs there was a presence of scabies, in the ears and nose lesions with secondary impetiginisation and wetting.

Medical Diagnoses: Contact impetigo; Scabies with secondary impetiginisation. Tonsillar hypertrophy; Pediculosis capitis; Hypotrophy.

Therapy: 1/2 FR $500 \mathrm{ml}$, sulfur paste for skin, Framykoin ung / twice daily / diet for larger children no. 13, dietary intake by mouth, problem with food intake - eats $1 / 4$ of food.

During five days of hospitalization was administered medicines as per the doctor's orders. Fucidin creme $1 \times 15 \mathrm{~g}$, Fenistil gto 1x 20ml gtt, Vermox tbl 6x $100 \mathrm{mg} 1-0-1$, $\mathrm{H} 2 \mathrm{O} 20.3 \% 3 \mathrm{~g}$. Examinations performed: ENT, dermatology, swab from skin of affected area.

Evaluation of Results with Focus on Pathology: FW 50/77, Leu 11.87, HGB 121. Due to Pediculosis capitis delicing was performed on the child. Sulfur paste was applied, the child was bathed in Hypermanganese, therapy administered + Biseptol 2x $1 / 2$ tbl,.

\section{Analysis and Interpretation}

During our observations, we identified serious shortcomings in hygiene, eating and speech development as a means of communication. The hygiene standard of the child is low. She is experiencing problems of $\mathrm{Pe}$ diculosis capitis, scabies and impetigo. The child does not have basic hygienic habits: does not cooperate with showering; cannot clean her teeth independently; does not wash her hands after using the toilet; refuses to eat hot food, only one $1 / 4$ of each serving - one reason for which may be the presence of ascarididae in the digestive system. She does not have the right weight for her age that a well-fed child should have. According to expert studies, the average weight and height of a girl in the 6th year of life is $21.5 \mathrm{~kg}$ and $120 \mathrm{~cm}$. The mother was repeatedly warned by a general practitioner about inconsistently administering antibiotics. For this reason, the child's condition worsened, leading to hospitalization. We tried to get her to cooperate, but there is a language barrier; the child does not know the basics of the Slovak language. This is a child who is about to begin the 1st year of elementary school and one of the criteria of maturity for school is knowledge of the language in which the child will be educated. The history shows signs of delayed development and recurrent episodes of child hospitalization are present. The child was pale, crying and 
restless during her stay. Physical examination did not show atypical findings on the skin.

The child also comes from a socially backward multi-child family where the risk of occurrence of CAN Syndrome according to the literature is higher. Hypotrophy in the child, considering the low social and economic status of the family, is related to failure to provide adequate nutrition, regular meals and healthcare. Due to the fact that the child has been repeatedly hospitalized over a period of a whole year, the parents show an interest in the child's health and thus the recurrence of illness in the child does not have to occur deliberately, but most of the time the disease will reoccur because of the inability or lack of knowledge of how provide adequate child care and due to neglect for prevention.

All the facts observed indubitably indicate that this is a case of a neglected child. This conclusion is also based on the information in the statements of several authors of the literature, for example, according to Supinova 2013 unfavorable factors in a family with a low social position have a negative impact on the psychomotor development of the child. Veleminsky 2009 described Deprivation Syndrome in neglected children, coupled with poor satisfaction of basic mental, emotional and social needs. The tearfulness and restlessness in the observed child may be a sign of this Deprivation Syndrome.

Despite the fact that we know the social background of the family to which the child returns, as stated by Skodacek 2015, it was difficult for the nurse to ensure adequate prevention. As the poor living conditions and the poor health situation of the Roma population is a widespread social problem requiring more systemic solutions, appealing to and educating the parents to improve the living conditions of the child, seemed to be a problem. In cooperation with the general practitioner, we could only emphasize repeatedly to the mother the need to improve the personal hygiene of the child and other family members. Preventive measures to maintain better health of the child were explained to her, especially during the winter months (layering of clothing, maintaining the right temperature), she was informed about diseases due to poor water and diet.

\section{Discussion}

From the child's history we found out that the child lives in a large family with low social and economic status, which may be one of the reasons for the neglect of the child. According to Caputova 2000 the worsened state of health of Roma children is also due to the fact that in Roma communities there are more cases in which the state of health of the child is caused by the neglect of parental care. Family is a significant determinant that influences the development of the personality of the child. It is primarily about the quality of family relationships and their ability to fulfil basic functions (economic, socializing, biological, emotional). According to Ondriova et al 2014, mothers from Roma communities have worse health care, more frequent incidence of smoking and alcoholism, poor housing conditions increasing the risk of stress and interpersonal conflicts. According to health statistics, their children have a lower birth weight.

One problem in poorer families is eating habits, or rather, the lack of certain dietary elements (e.g. protein, fruit). Alongside the material deprivation, a serious problem is the unhealthy diet in regard to calories, which are particularly important for children. These children often have a tendency towards malnutrition. A child that eats too little suffers from lack of appetite, low weight, and growth lag may also show other warning signals that point to inadequate nutrition: the child is not interested in its 
surroundings; can often be irritated; avoids eye contact; does not reach developmental milestones at the same age as other children.

According to the findings of Kovac et al 2009 children from poorer families tend to have complications from prenatal development, they are often born with low birth weight, with health complications, have more frequent injuries in their childhood; they are more often hospitalized than children of families with higher socio-economic status. The poor lifestyle of some members of the Roma community, often associated with unhealthy eating, alcoholism, tobaccoism, overcrowded housing, poor hygiene habits etc., have a significant impact on the increased incidence of some, especially infectious diseases. Some of the most common diseases that have been seen and are still seen in some Roma communities are scabies, infectious respiratory diseases, tuberculosis, meningococcal meningitis, hepatitis type $A$ and $B$, dysentery, salmonellosis, ascariasis, fleas, bed and hair lice or other parasitic insects.

It is also worth mentioning that the upbringing of children of families living in such an environment is less favorable for the development of the personality of the child. Parents are less sensitive to the special abilities of their children and consider it less important to support them in their development. Fischer and Skoda 2009 claim that a large proportion of six-year-olds are not ready for successful study of the first school year. These children come from broken families, from an environment with low social and educational motivation, are socially isolated, lonely, nobody pays attention to them, plays with them or speaks to them. As a result, the child lags behind in development and also fails at school. According to Padysakova 2006 it is natural that the child does not consider education and school to be important if the family itself does not understand education as a positive value and one of the most important input for the future for its child if it does not show interest in the child's school work. Matejcek 2008 claims that Roma children do not have hygienic habits and do not speak the language they will be taught in. They come to school unprepared and hungry, and find themselves in an environment that is foreign to them.

\section{Conclusion}

For the healthy development of a child, it is essential that the basic needs of the child are met, otherwise deprivation occurs. The environment in which a child grows up plays an important role in the formation of the personality of an individual. Pemova, Ptacek 2016. A child has the right to grow up in a family where they are given love, security, safety and the necessary conditions for their healthy physical, mental and social functioning. If one of these aspects is compromised, the growth and development of the child is threatened.

\section{References}

1. CAPUTOVA Z (2000) Cruelty Abuse and Neglect of Children. Pezinok Jaspis 200072 pgs ISBN 885576260.

2. DUNOVSKY J, DYTRYCH Z, MATEJCEK Z et al (1995) Cruelty, Abuse and Neglect of the Child 1 st edition Prague Grada Publishing 1995248 pgs ISBN 8071691925.

3. DUNOVSKY J (1995) Cruelty, Abuse and Neglect of Children in the Light of the Declaration on the Rights of the Child from 1989 and the Recommendation of the Council of Europe from 1992 In Amireport III 1995 issue 2 pp 7377.

4. FISCHER S, SKODA J (2009) Social Pathology Prague Grada 2009 p 345 ISBN 9788024727813.

5. HROMKOVA M (2006) Sexual Abuse of Children In Diagnosis in Nursing Prague 
Promediamotion issue 62006 p 289-290 ISBN 1801-1349.

6. KOVAC P et al (2009) Cruelty and Abuse of the Child - minimum for the practisingpaediatrician In Pediatricts for Practice vol 10 issue 12009 pp 49-51 [cit 17 February 2018] ISBN 1336 8168. MATEJCEK Z (1995) Prevention of Child Cruelty In Czech Medical Journal 1995 vol 134

7. issue 11 pp $339-341$.

8. MORGAN H, PORTNER H (1995) Providing Preventive Services in an Urban Setting
In Children today 1986 November Grada Publishing 1995 p 398 ISBN 8071691682.

9. ONDRIOVA I, MROSKOVA S, CINOVA J (2014) Cruelty Abuse and Neglect of the Child in Healthcare Practice Paediatrics Bratislava 92 pp 9194 ISSN 1336863X7.

10. PADYSAKOVA H (2006) Social Groups at Risk Nursing Aspects In Nursing Horizon vol 3 issue 2 pp 5260 ISBN 13365606.

11. PEMOVA T, PTACEK R (2016) Neglect of Children Prague Grada p 567 ISBN 9788024756950 . 